\title{
The Evolution of Urban Living Concept in Internet Age Chengeng Cui
}

\author{
Shandong University of Arts, Shandong, Jinan, 250300
}

Chengeng_cui@163.com

Keywords: Internet; Urban; Residential concept

\begin{abstract}
The internet age is a new mankind's way of communicating. The changed way of people communicate with each other is integrated into the concept of people's living. This will greatly change the concept of people. At the same time, the internet is also a technical platform, which keeps the literature and art and business interaction related to people's lives together from a multitude of perspectives. so that the concept of people living in the city has an essential change. From the analysis of the characteristics of traditional Chinese residential concept, this paper summarizes the development characteristics of the internet era searching for the feasibility of urban living concept in the internet age around the difference of modern living environment and traditional living environment. From enlightening exploration, the inheritance and development of traditional concept of living in the modern internet living environment is thoroughly studied.
\end{abstract}

\section{CLC number: TP135 Document identification: A}

\section{Introduction}

With the constant development of science and technology, the informationized life has come to us. The current civil life habits and life style has a great change. This is a new life pattern. This pattern takes bit as a unit, which is the signature beginning of the internet age. The arrival of internet age promotes the rapid development of the whole human society. The information sharing has become the common theme of the world. This idea has been deeply integrated into our lives and work and has an important influence on our ideas, which has provided a clear directionality for development.

The information sharing is the most important symbol of the internet age. No matter where people live, which area people live in, with an internet, you can master all the network information. The final result of the development of the internet is to create a more suitable urban environment for human living. The Internet age makes people's living concept have a great change. From the changes in the development of houses and buildings of humans, it can be seen obviously that the concept of human living is changing. The change of these concepts is closely related with the society in the development of science and technology, which is the direct reflection of whole ideology at present. With the change of the demand of residential housing commercialization in our country and the change of demand, improving the living standard and family living environment to meet the needs of society has become an urgent hope and power.

Especially in the past twenty years, the internet technology develops continuously making the change of people living concept. The change of living concept makes the proportion of real estate investment accounted for $1 / 4$ of the total social investment. About one billion square metres of residence are put into use every year. It's not hard to see that with the continuous development of the internet era, people will have new requirements for the new living environment and concept in the next few years.

\section{Fusion of Internet concept and living the concept}

\section{A. The relationship between internet and living}

The design of space environment in the information age is in keeping with the trend of contemporary design. Science and art help each other forward, enrich and innovate, nurturing the 
contemporary environmental space design like the sun and the rain and dew, which provides a broad development prospect and endless power for it.

The wide application of new achievements and new products of internet high technology in design constantly increases the technological content of the home environment and makes the design of space environment rich and diverse, and the technique flexible. In addition, the interior environment design in the Internet age is an integral part of the humanities. Emphasizing reason is beginning to be replaced by emotional demands. The distance between design and art has gradually become blurred. So much as many interior design works itself is art.

The interior design of art has been recognized by many interior designers, which is being applied to practice by many designers. In sum, the contemporary designing is the use of advanced ideas with visual art form to express, conversely, expressing and transferring scientific ideas with emotional means of artistic expression. Exploring the universe theory with the scientific humanity and expressing human feelings with artistic universe theory are the true portrayal of space environment design in information age.

\section{B. Internet achievements applications}

The technology of internet age has driven the development of human civilization and social progress. The purpose of technological innovation is to transform the natural environment into a man-made environment that can make people live more comfortable and harmonious. Interior space space is a "man-made environment" that is closely related to people's lives and narrowed.

The purpose of interior design is to make people more comfortable living, learning and working in residential environment. The contribution of science and technology adds a wealth of elements to the interior space environment design. The household electrical appliance is a best example.

Before 70s of last century, designers need not consider the space of electrical equipment in addition to lighting. The residential space layout is simple, only the bedroom, bathroom, kitchen.

In middle of 1980s, washing machines, televisions, refrigerators, air conditioners and other household appliances gradually came into the family. Designers began to consider the various factors of residential appliances in home furnishing function. The functional space of restaurant and living room is gradually clear.

To the 21 century, the development of household electrical appliances is more rapid. The interior space distribution with various different functions household electrical appliances combination as the center becomes more and more clear, besides bedroom, living room, dining room, bathroom, kitchen. There are television, music center, DVD home theater audio-visual space, office space with computer equipment, scanner, printer, and sports and recreational space with display treadmills, fitness equipment. These new household electrical appliances emerge in an endless stream put forward higher requirements to the residential design. As shown in Figure 1.

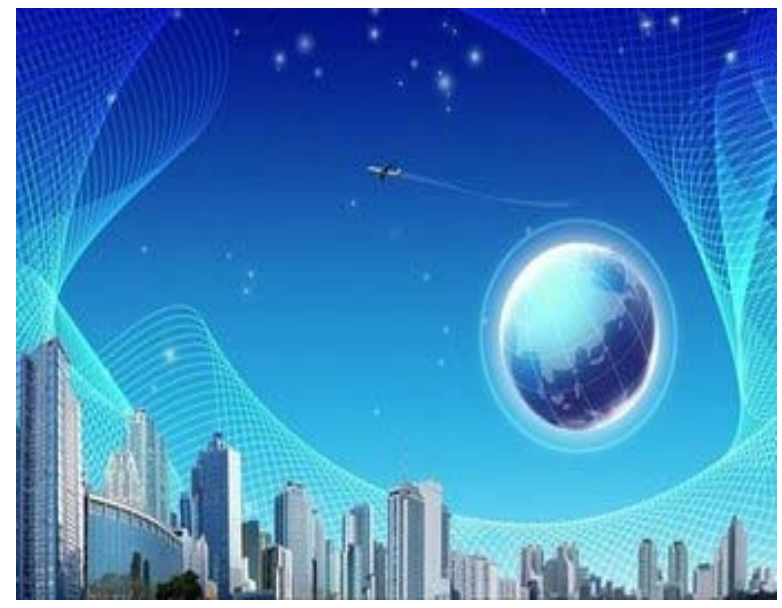

Figure 1. Internet age urban diagrammatic sketch

C. The impact of the Internet on the concept of living

In the information network, the remote control and digital home household electrical appliances products not only make people's lives more comfortable and convenient, but also change a new life 
way. This reflects that the trend of digital network era dwelling pattern interior space environment design is a miniature of the current social development.

The purpose of design is to serve people. It is necessary to integrate into the society and people's lives in order to truly reflect its value. If the design breaks away from the community that is just a water without a source, the wood without roots. Environmental space, people's culture, psychology, habits and other factors from different perspectives, which makes the design fully reflect its maximum value. People's routine life is closely related to network in the network information era, which highlights the temper of times and has the visual impact and aesthetic feeling. This takes the society as the ultimate starting point. This is the essence of interior space design.

In the Internet age, the building of people living environment can also be called a change of the living. The function of its living environment is the indirect expressing information the concept of living. With the rapid development of internet technology, the impact on the living environment is gradually intervened. Residential environment shows information approach in internet age. The current people's living concept is not just a single residence, at the same time completing more functional requirements. By simple orientation and voice, the thing can be completed that it may take a few days to complete in the original era when there was no internet. The current concept of living has changed from the original single user into an active operator. What merits our primary concern is that the speed of information dissemination of the internet age is much faster than the traditional age. That not only increases the demand for knowledge, but also extends the information age width in network age, which causes us to change unconsciously. The age of internet has come, which gives me a more positive direction for the needs of living.

\section{The concept of urban living in the Internet Age}

In twenty-first century, internet information technology and automatic control technology are used in construction. As the carrier of the living environment, the residential intelligent requirements also showed diversity. What we first think is "intelligentialized building". The term "intelligentialized building" is a special term emerged as the times require with efficient, safe, comfortable and convenient living environment in the era of network information. The emergence of smart home and its own characteristics also cause intelligent home network system arise at the historic moment. Efficient network communication facilities and perfect information processing terminal equipment is the basis for the realization of the system. Anti-theft system, fire prevention, explosion proof, leakage proof alarm system brings high security to the residential. The automation and intelligentialize of household electric appliances equipment brings the specific function of home network intelligent such as comfortable living environment, convenient resource use and networking payment method. It can meet the demand of material network cultural life in the information age.

\section{A. Epoch development history}

The early intelligent building is a commercial and office intelligent building. In 90's of 20th century, some developed countries in Europe and America have put forward the concept of intelligent building (SmanHome). The basic idea is "the communication apparatus, household electric appliances and home protective device that information related in the family are connected to a home intelligent system through home bussing technique connected to a home furnishing intelligent system. Running centralized or remote monitoring, control and family affairs management is to keep harmony and coordination of the household facilities and residential environment".

The new way of communication is not restricted by region and time. The people's communication range is greatly expanded. Information technology promotes the diversification of communication approach and communication channels, which makes interpersonal communication show a kind of openness and diversity. Communication used the information technology is usually not face-to-face. Interactive both sides use symbols to represent their identity in the virtual information space. This virtual identity also eliminates the hierarchic difference.

Building is the people-oriented. Building is used by people. It is an inevitable trend that building 
should adapt to the change of people's interaction. For architects, If the architect wants to make the design work be accepted by the public, carefully digging the aesthetic needs under too much information hidden in the surface of the building. From the development of network era, people's interaction with the Internet has also been taken seriously. Because of the increasing interaction, people's life style has changed gradually. The change of concept reflects that people's lifestyle in internet age affects the personal living style, and must also influences the design approaches of modern urban building. This will inevitably lead to new life characteristics and living concept in new age.

Table 1 Concept of living in the Internet Age

\begin{tabular}{ccc}
\hline $\begin{array}{c}\text { Sense } \\
\text { networking }\end{array}$ & Residential use & Right \\
\hline Voice gesture & Vision & Full equality \\
Characters & Vision & Literate man \\
Image & Vision & $\begin{array}{c}\text { Everyone is } \\
\text { equal. }\end{array}$ \\
Multi-Media & Visual-auditory & Participant \\
\hline
\end{tabular}

\section{B. Prospects for development of the living concept of internet}

As early as the end of the last century, the concept of "intelligent residential" was introduced in 21 th Century future residential development trends.

The definition of smart home is that by using the method of system integration, computer telecontrol technology, information technology, communication technology and architectural art are organically combined. From users' information service, information resource management and automatic monitoring of equipment and optimal combination of building facilities, the information obtained is suitable for the development of society and knowledge economy and has the characteristics of safety, comfort, convenience, high efficiency, flexible.

Intelligent residential is the inevitable product in the information age, and formed from the need for people to live with the development of intelligent technology and the progress of the society. It contains equipment physical building environment and software environment includes management and service that related to the professional knowledge of architecture, electrical, communications and computer. The basic conditions for the construction of smart homes has three points: (1). The network system can be connected with the outside; (2) Home automation solution system amount to residential backbone; (3) provide a variety of services through the network.

In the morning, smart home system wakes up your family from the dream with soft music and light; before you wash after entering the restaurant, the breakfast is ready. According to the instruction information of the previous night before going to bed which is set in the central controller, the steaming hot coffee is emitting the tantalizing smell. The sausages and milk in the microwave were hot. The newly baked bread jumped out of the toaster. Start eating breakfast, turn on the TV, what the video automatically broadcasts is that we did not watch the second half of the live game because of the time relationship at midnight: finish the breakfast before going out, press a key of the central controller in the door. The lighting and electrical equipment no one use will automatically shut down, you can go to work. Because at this time, the home security and monitoring system automatically go into a state of alert. At noon, your mobile phone suddenly received the alarm call from home -- who is trying to enter your home, triggering the safety precaution system at home. at the same time, the system automatically dials your phone, also sends alarm information to the community security center. You immediately open computer and login remote monitoring system. You can see the real-time image captured by the camera at home in your house. The thief pries the door into the house. Community security personnel will quickly come to your home to seize them.apartment management office also called you that little damage has been 
caused. The thief has been sent to the nearby police station. In the afternoon, you received a phone call from your children, saying that he had finished his homework and want to watch TV or surf the internet. So you connected to the site with using the desktop computer, entering the user name and password. You enter the control page and unlock the network information. Then you tell your children they can enjoy themselves. on your way home from work, you use the phone to remotely connect the home central controller voice system in the car for giving orders: let the rice cooker cook rice over a slow fire; prepare hot water for bath; remote open the air conditioning in the living room; after going back, you can enjoy the cool in your home. In the evening, Smart home system received the information reminder. Tell you to pay water rates, electricity charge, gas bill and property management fees. Turning on the computer and logining the service system, you can pay directly on the internet. As shown in Figure 2.

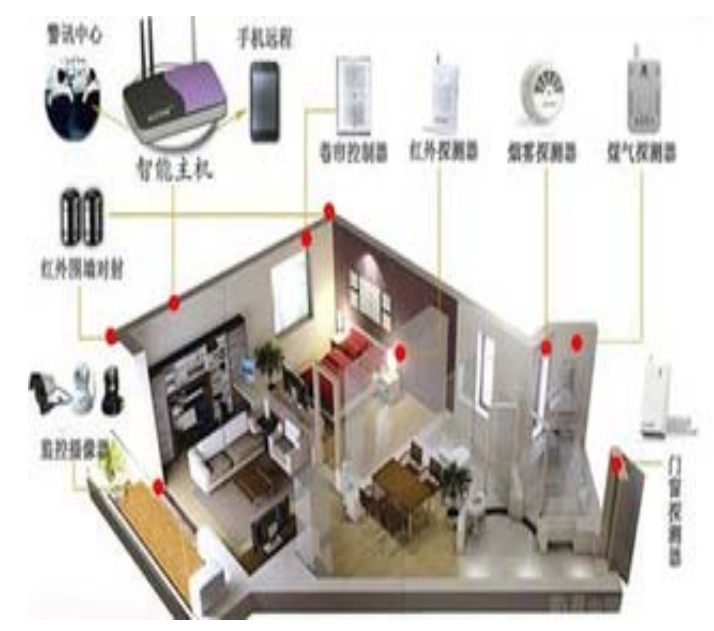

Figure 2. Diagrammatic sketch of living concept in the Internet age

\section{Conclusion}

In the Internet age, the concept of urban living is diversified. and the urban living environment has also entered into the era of informatization, ecologicalization with multivariate themes highly integrated. This paper analyses and studies the urban life in internet era from many ways, exploring the change of people's living concept and the direction of demand under new background, seeking a new living concept that adapted to the natural and harmonious development of people in the modern internet era and highly integrated the environment, energy and ecology.

\section{Reference}

[1] Lecomte J, Lagneaux D. [Léon Fredericq and the concept of regulation in the physiology of living systems][J]. Revue Médicale De Liège, 1986, 41(20):840-2.

[2] Coward R T, Cutler S J. The concept of a continuum of residence: Comparing activities of daily living among the elderly[J]. Journal of Rural Studies, 1988, 4(2):159-168.

[3] Billerandorno N, Agich G J, Doepkens K, et al. Who shall be allowed to give? Living organ donors and the concept of autonomy.[J]. Theoretical Medicine and Bioethics, 2001, 22(4):351-368.

[4] Hahn A G, Gore C J, Martin D T, et al. An evaluation of the concept of living at moderate altitude and training at sea level is [J]. Comparative Biochemistry \& Physiology Part A Molecular \& Integrative Physiology, 2001, 128(4):777-789.

[5] Plieth W. Electrochemical deposition: the concept of residence times in structure development[J]. Journal of Solid State Electrochemistry, 2004, 8(6):338-345.

[6] Villarroel J D. Environmental judgment in early childhood and its relationship with the understanding of the concept of living beings[J]. SpringerPlus, 2013, 2(1):87. 
[7] Yang Z. Artistic Conception and the Environment in the Concept of Living Chinese Inhabitation Theory under the Perspective of Traditional Literatus[J]. Journal of Beijing University of Civil Engineering \& Architecture, 2015.

[8] Babitsch B, Hofreuter K. [Continuative approaches of social structure for health inequality research--which perspective opens up the concept of living conditions?].[J]. Gesundheitswesen, 2012, 74(3):10-8. 